\title{
A Retrospective Clinical Study to Evaluate Mineral Trioxide Aggregate (MTA) As A Direct Pulp Capping Agent In A One-Visit Protocol
}

\author{
Patrick J. Petley \\ West Virginia University
}

Follow this and additional works at: https://researchrepository.wvu.edu/etd

\section{Recommended Citation}

Petley, Patrick J., "A Retrospective Clinical Study to Evaluate Mineral Trioxide Aggregate (MTA) As A Direct Pulp Capping Agent In A One-Visit Protocol" (2012). Graduate Theses, Dissertations, and Problem Reports. 3540.

https://researchrepository.wvu.edu/etd/3540

This Thesis is protected by copyright and/or related rights. It has been brought to you by the The Research Repository @ WVU with permission from the rights-holder(s). You are free to use this Thesis in any way that is permitted by the copyright and related rights legislation that applies to your use. For other uses you must obtain permission from the rights-holder(s) directly, unless additional rights are indicated by a Creative Commons license in the record and/ or on the work itself. This Thesis has been accepted for inclusion in WVU Graduate Theses, Dissertations, and Problem Reports collection by an authorized administrator of The Research Repository @ WVU. For more information, please contact researchrepository@mail.wvu.edu. 
A Retrospective Clinical Study to Evaluate Mineral Trioxide Aggregate (MTA) As A Direct Pulp Capping Agent In A One-Visit Protocol

Patrick J. Petley, DMD, MBA

\author{
Thesis Submitted to the \\ School of Dentistry \\ at West Virginia University \\ for the degree of \\ Master of Science \\ in Endodontics
}

in partial fulfillment of the requirements

Thomas Borgia, DDS, MPH, Chair

Michael Bagby, DDS, MS, PhD

Elliot Shulman, DDS, MS

Department of Endodontics

Morgantown, West Virginia

2012 


\begin{abstract}
The purpose of this study was to demonstrate the long-term success that can be achieved by the use of Mineral Trioxide Aggregate (MTA) as a pulp capping agent, demonstrate the simplicity of the procedure, and overcome the commonly held objections of cost, difficult handling characteristics, and the need for two appointments to complete the procedure.

A single visit protocol was utilized in the completion of forty-eight pulp cap procedures with twenty-seven procedures available for recall. The MTA pulp cap was covered with glass ionomer liner and then restored with a bonded composite or amalgam. Teeth were evaluated for sensitivity to percussion, cold testing, and periapical radiograph at follow-up appointments. A success rate of over eighty-five percent was achieved in this study. MTA has been demonstrated to be the material of choice and gold-standard for pulp capping procedures. MTA is biocompatible, less cytotoxic than calcium hydroxide, provides a bioactive benefit and a bacteriostatic seal. The specific details of the histological pulpal response to MTA and other pulp capping agents, requires additional investigation.
\end{abstract}


Vitae

Patrick J. Petley, DMD, MBA

\section{Education and Training:}

- Masters of Business Administration, M.B.A. Waynesburg College, Waynesburg, PA

- Doctor of Medical Dentistry, D.M.D. School of Dental Medicine, University of Pittsburgh, Pittsburgh, PA

- Bachelor of Science, Chemistry, BS College of Arts \& Sciences University of Pittsburgh, Pittsburgh, PA
2002

1984

1979

\section{Professional Experience:}

Comprehensive Family Dentistry, Bethel Park, PA

1986 - present General Dentist - Sole Proprietor

- Established a patient focused family dental practice within a highly competitive area.

- Coordinated all aspects of business startup: formulation of business plan and cash flow projections, analysis of demographics and local competitors for site selection and secured financing.

- $\quad$ Recruited, trained and managed dental office staff.

- Sustained repeat clientele through excellence in care and cultivation of trusting relationships.

OnSite Dental Care, Inc., San Mateo, CA

2007-09

Reachout Healthcare America, Phoenix, AR

2007-09

Dentist - Military Subcontractor

- Civilian treatment provider of dental services to U.S. military personnel.

- Travel to military base locations.

- Treatment is provided in mobile dental units provided by subcontractor.

Penn State University, Beaver Campus, Monaca, PA 2007-08

- Presenter of "Aging and Oral Health-Related to Quality of Life in Geriatric Patients" for Personal Care and Nursing Home Administrators.

Maverick Dental Laboratory, Monroeville, PA 2005

Technical Director

- Consultant position as Technical Director.

- Position was primarily a customer service role for a dental laboratory start-up seeking contributions from a D.M.D., M.B.A.

Westinghouse Electric Corp., Beaver, PA

1980

Engineer Trainee, Circuit Breaker Plant

Fortune 500 training in manufacturing facility. New product development and research, CAD-CAM training, assembly group supervision, efficiency study, Quality Circle Pilot Program, and engineering training. 


\section{ACKNOWLEDGEMENTS}

I would also like to thank Dr. A. Thomas Borgia, Chairman, Endodontic Department, for granting me the opportunity to become an endodontist. As a mentor you have demonstrated great depth of knowledge and experience, exceptional clinical competence, tremendous patience, dedication, leadership, encouragement, and the ability to assist a mid-career general dentist successfully navigate an endodontic residency. Your commitment to excellence has restored the quality of the West Virginia University Graduate Endodontic Department.

I would like to thank Dr. C. Russell Jackson, Director, Graduate Endodontic Program, for his knowledge and experience shared so unselfishly during my endodontic residency. You were always available, positive, and supportive. I appreciate both our professional relationship and personal friendship. I hold you in very high regard as a dental clinician, endodontic instructor, and an exceptional gentleman. I admire the life-time commitment you have given to dental education.

I would also like to thank Dr. Elliot Shulman, Chairman, Pediatric Dentistry, for his positive acceptance of my proposal and his personal assurance that the Pediatric Dentistry Department would provide the patients necessary for a statistically meaningful study.

I would like to thank Dr. Michael Bagby, Chairman, Restorative Dentistry, for guiding my investigation and literature review as it pertained to the use of MTA as a pulp capping agent. I admire the depth of your education, experience, and knowledge. I also greatly appreciate the collegial relationship we have enjoyed.

Thank you also to Dr. Takashi Komabayashi for voluntarily assisting me across the finish line as I completed this research study. 


\section{TABLE OF CONTENTS}

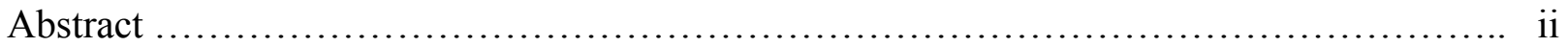

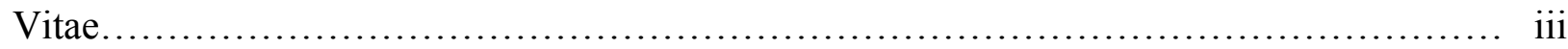

Acknowledgment............................................................ iv

Table of Contents...........................................................

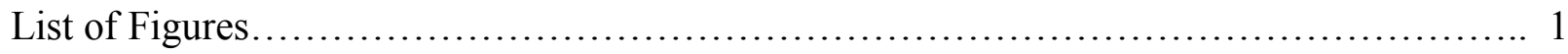

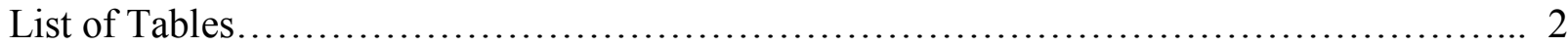

Introduction:

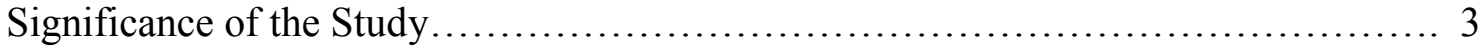

Background........................................................ 4

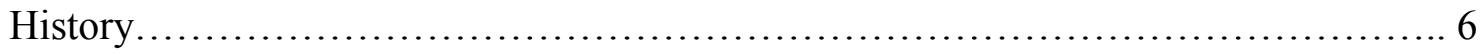

Statement of the Problem............................................... 8

Review of the Literature.................................................... 8

Materials and Methods:

Candidate Selection......................................................... 15

Tooth Selection..................................................... 15

Treatment............................................................. 16

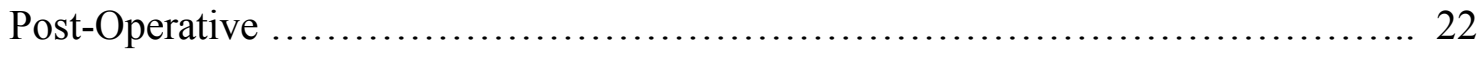

Success/Failure ......................................................... 22

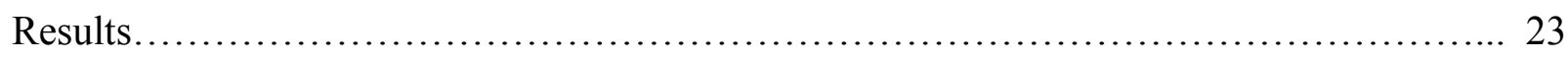

Discussion............................................................. 26

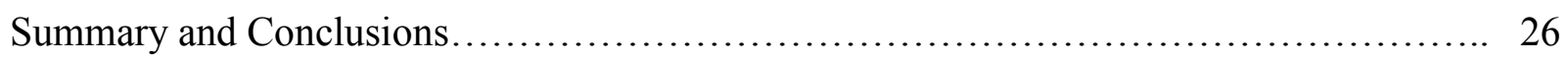

References............................................................. 29 


\section{LIST OF FIGURES}

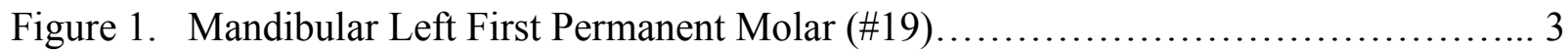

Figure 2. Maxillary Left Central Incisor $(\# 9)$.................................... 5

Figure 3. MTA Package....................................................... 7

Figure 4. 1.0g Foil Packet.................................................... 7

Figure 5. Dentin Bridge Formation at MTA-Pulp Interface.......................... 11

Figure 6. Gross Caries (\#19), Excavation of Caries.................................. 17

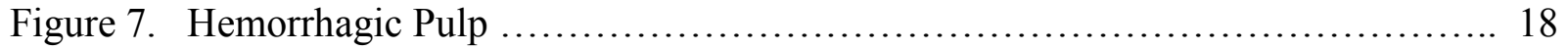

Figure 8. Hemorrhage Control............................................ 18

Figure 9. Armamentarium................................................. 18

Figure 10. Fractional Dose of MTA powder...................................... 18

Figure 11. MTA Dose, Sterile Water, Spatula, PFI Instrument....................... 18

Figure 12. Wet MTA, Powder to Sterile Water, 3:1 Ratio............................ 19

Figure 13. Loading Bone Carrier Device.......................................... 19

Figure 14. Dispensing Desired Amount........................................ 19

Figure 15. Large Pulpal Exposure......................................... 20

Figure 16. $1.5 \mathrm{~mm}$ MTA Layer................................................ 20

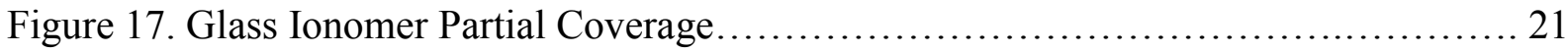

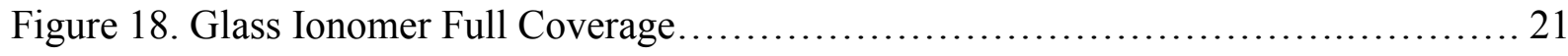

Figure 19. Light Cure Composite............................................... 21

Figure 20. Completed Restoration.......................................... 21

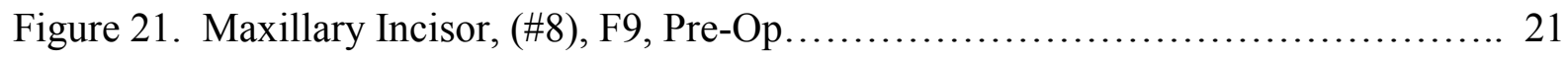

Figure 22. 5 Month Recall............................................... 21

Figure 23. Mandibular Left First Molar (\#19), F8,Pre-Op......................... 28

Figure 24. Post-Op. ...................................................... 28

Figure 25. Dentin Bridge, 10 Month Recall..................................... 28

Figure 26. Maxillary Left Second Biscuspid, (\#13), M11, Post-Op. ................... 28

Figure 27. Apexogenesis Progression, 3 Month Recall............................ 28 


\section{LIST OF TABLES}

Table 1. Cases Available for Recall.............................................24

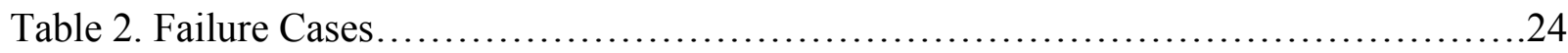




\section{Introduction}

\section{Significance of the Study}

It has often been stated that the best endodontic treatment is no treatment at all (M.

Trope, personal communication, August 13, 2011). Frequently, patients present with deep

carious lesions that do not demonstrate the signs and symptoms of irreversible pulpitis. Children and adolescents may also show radiographic evidence of incomplete apical root formation. This retrospective study is intended to provide new information to better identify the cases that would most likely benefit from an already proven, cost effective, non-invasive, predictable treatment procedure that is simple, inexpensive and can be completed in one appointment by endodontists, pediatric dentists, and general dentists. This study will present evidence to support the benefits of conservative treatment and avoidance of extraction or conventional endodontic therapy, especially the myriad complications associated with treating teeth with immature apices. The most beneficial use of this procedure is when caries have reached pulpal tissues but apical root formation is incomplete (Fig. 1).

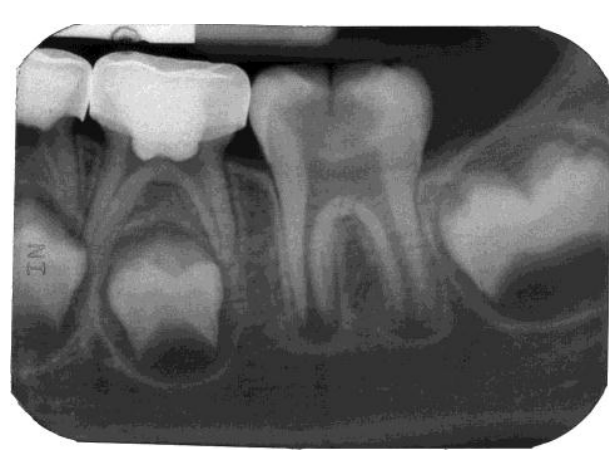

Pre-Op

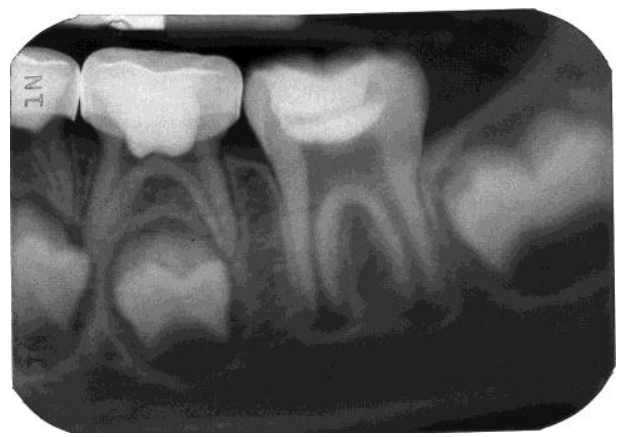

Post-Op

Figure 1. Mandibular Left First Permanent Molar (\#19) M6, Deep Caries - Incomplete Root Formation 


\section{Background}

The objective of this study was to evaluate the outcomes of single visit, Mineral-Trioxide Aggregate (MTA) vital pulp capping procedures on dental patients seven to twenty-five years of age presenting with deep caries in non-restored permanent teeth or traumatically fractured anterior teeth with pulpal exposure, and a diagnosis of reversible pulpitis. Pulp capping can avoid a more invasive and potentially far more difficult endodontic procedure, particularly in patients that present with immature apical formation. Routine endodontic therapy is considered to be a moderately invasive, complex, and time consuming procedure. Child and adolescent patients frequently have significant difficulty tolerating the complexity and duration of conventional root canal therapy. The treatment provider may be distracted or unable to manage patient cooperation issues related to treating child and adolescent patients prior to and during endodontic procedures. Very often, just the administration of local anesthetic can be a timeconsuming persuasive endeavor or even an impossible accomplishment. These additional patient management responsibilities can compromise clinical outcomes. The inability of this age group to tolerate one hour or longer appointments may require multiple office visits in order to complete an endodontic procedure. Multiple visits are not reasonable from a cost perspective for the provider and are inconvenient for the parent or guardian. In many cases, the procedure must be completed with intravenous sedation or general anesthesia, reflecting a very significant increase in resources, cost, and risk.

The intention of this clinical study is to clearly demonstrate that pulp-capping procedures with MTA are relatively simple to complete and can routinely be performed by endodontists, general dentists, and pediatric dentists. The study will demonstrate that with dental dam isolation, routine caries removal and cavity preparation, disinfection, hemorrhage control, proper 
placement of the MTA and final restoration, a vital pulp cap procedure is both superlative in preserving the vitality of the pulp and is also far more cost effective than endodontic treatment and crown placement.

Additionally, this study intends to establish a rationale to decrease the number of extractions and conventional endodontic procedures performed on teeth that could otherwise be more ideally treated with vital pulp therapy. Following strict pre-treatment pulpal status criteria for case selection, proper placement of a direct pulp cap of MTA in a single-visit protocol results in a significantly greater benefit at a much lower cost than can be obtained when compared to other pulp capping materials, endodontic therapy or extraction.

Furthermore, this study will minimize or eliminate the common objections to the use of MTA including cost, handling characteristics, and setting time. The objection due to discoloration remains an issue in anterior teeth with both white and gray MTA (Fig. 2). The bioceramic compounds now available may provide a preferential material for anterior applications, but this remains to be studied.
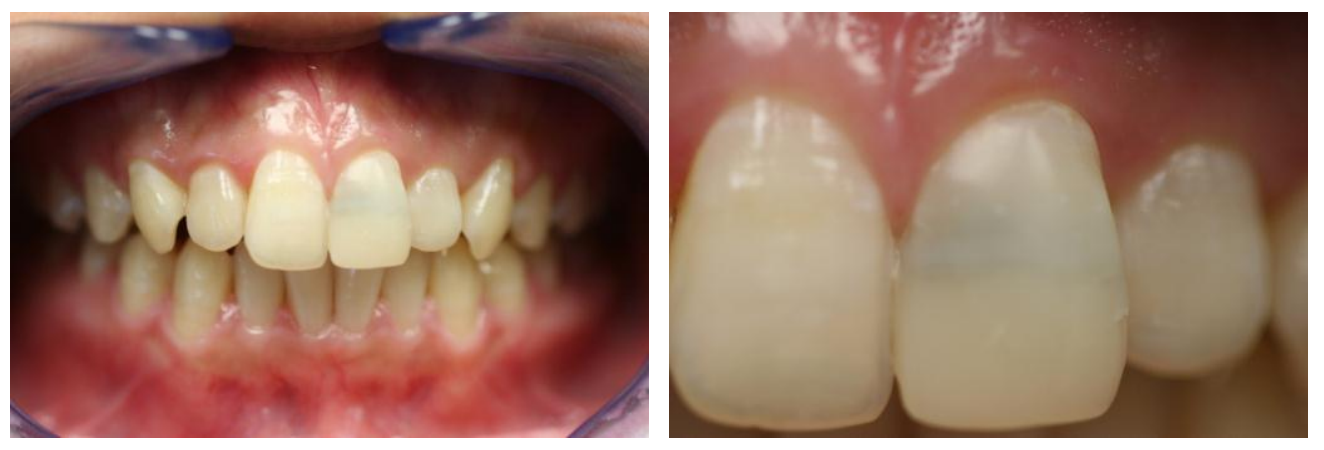

Figure 2. Maxillary Left Central Incisor (\#9), F25, White MTA, 2 Week Post-op, Discoloration 
Future long-term studies on this age group of patients may demonstrate that cariously exposed pulps of teeth treated with MTA and conservative restoration, exhibit greater longevity than endodontically treated teeth followed by crown placement.

\section{History}

As defined by the American Association of Endodontists (AAE) in 1981, " Direct pulp capping is a well-established method of treatment in which the exposed dental pulp is covered with a material that protects the pulp from additional injury and permits healing and repair" (Accorinte et al., 2009). This is the preferred pulpal preservation treatment because it promotes healing by regeneration rather than repair (Witherspoon, Small, \& Harris, 2006).

Philip Pfaf first documented pulp capping in 1765 using gold foil (Hasheminia et al., 2010). Davis used a complex of zinc sulfate, calcium sulfate, and zinc oxide for pulp capping in 1923 (Hasheminia et al., 2010). In 1930, Hermann used calcium hydroxide for pulp capping for the first time (Hasheminia et al., 2010). Calcium hydroxide remained the standard for pulp capping until the 1990 ees (Hasheminia et al., 2010). MTA was introduced in 1995 by Torabinejad as a bioactive, endodontic repair material (Hasheminia et al., 2010).

The first publication on MTA was by Torabinejad in 1993 (Pitt Ford, Mannocci, \& Woolford, 2007). This was then followed by a series of reports in the years between 1995-2007 (Pitt Ford, Mannocci, \& Woolford, 2007). MTA was given approval for endodontic use by the U.S. Food and Drug Administration in 1998 (Roberts, Toth, Berzins, \& Charlton, 2008). Toabinejad published a clinical review of MTA in 1999, which was then followed by commercial availability through DENTSPLY International (Pitt Ford, Mannocci, \& Woolford, 2007) (Fig. 3, 4). 


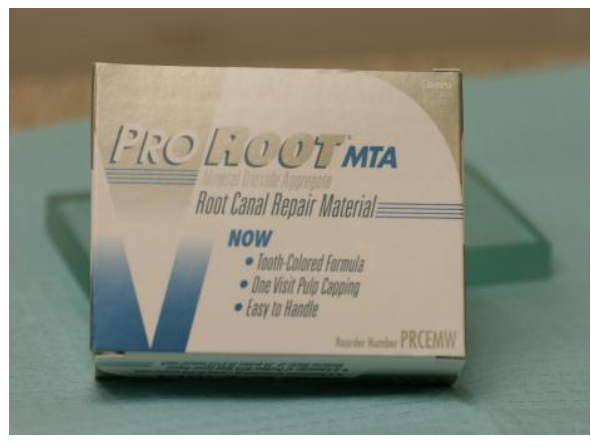

Figure 3. MTA Package Water pipette

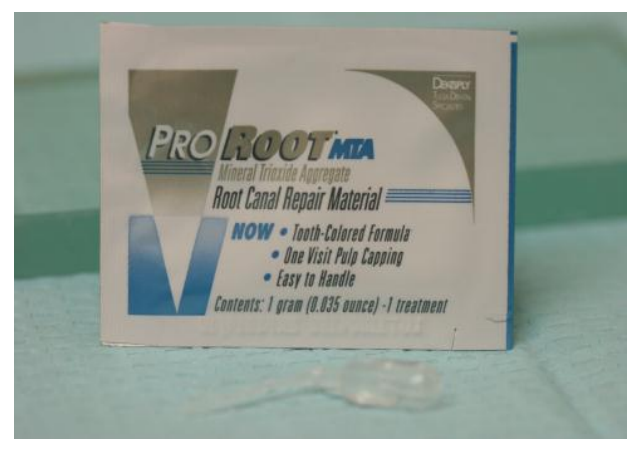

Figure 4. 1.0g Foil Packet with Sterile

MTA has become an appropriate material for pulp capping due to its biocompatibility, sealing ability, prevention of bacterial leakage, radiopacity, high $\mathrm{pH}$, favorable compressive strength, continual calcium release, and long-term stability in the presence of fluids or moisture (Pitt Ford, Mannocci, \& Woolford, 2007). Many animal and human studies have reported exceptional results for MTA when used as a pulp capping material. Farsi reported a 93\% success rate after twenty-four months (Parirokh \& Torabinejad, 2010). Bogen reported 97.6\% success treating carious exposures with MTA (Parirokh \& Torabinejad, 2010). Mente et al. (2010) reported $78 \%$ success with MTA and $60 \%$ success with calcium hydroxide in a study of pulp capping procedures completed by dental students and dentists. Min, in a human third molar study of mechanical pulp exposures, reported that all of the MTA procedures showed dentin bridge formation as compared to $60 \%$ for calcium hydroxide (Parirokh \& Torabinejad, 2010). Histological pulpal response to MTA is characterized by minimal inflammation, thicker and more complete dentinal bridge formation when compared to calcium hydroxide, and the presence of odontoblast-like cells (Paranjpe, Zhang, \& Johnson, 2010).

MTA is considered to be a biocompatible material. An accepted definition of biocompatibility is, "the ability of a material to perform with an appropriate response in a specific application" (Williams, 2008). With regard to specific interactions between biomaterials 
and local and systemic tissue host response, three different types of biocompatibility exist: inert, bioactive, or biodegradable (Blokhuis et al., 1999). Bioinert materials cause no host response, although the absence of a chemical interaction between material and host is not advantageous (Blokhuis et al., 1999). Osseous biocompatibility was greatly enhanced in the 1970 s by the development of bioactive materials. Unlike bioinert materials, bioactive materials cause an interaction between a biomaterial and the surrounding host tissue at the material host interface. A very favorable bioactive property is the beneficial interfacial tissue response caused by the biodegradation products of a bioactive material (Blokhuis et al., 1999). In other words, the release or presence of specific biodegradation products can cause a favorable local tissue host response, thus becoming, ,bioactive ${ }^{e e}$. MTA is a bioactive material and elicits a specific response when placed on pulpal tissue by induction of endontogenic differentiation (Guven et al., 2011).

\section{Statement of the Problem}

Although the literature has demonstrated MTA to be the gold standard of pulp capping materials, the routine use of MTA has not gained widespread acceptance. Can a single appointment MTA pulp cap procedure demonstrate acceptable clinical success?

\section{Review of the Literature}

Calcium hydroxide remains the material of choice for many clinicians. The ideal result of pulp capping procedures is reparative dentinogenesis with no concomitant inflammation. Pulpal repair is a complex process, the histological complexities and specific mechanisms of which are not yet fully understood. During the reparative process after pulp exposure, primary odontoblasts are lost and replaced with newly differentiated odontoblast-like, progenitor cells. Odontoblasts are end stage cells and cannot undergo cell division. A sequential process of cell proliferation, migration, and differentiation precedes calcific matrix secretion at the exposure 
sight (Okiji \& Yoshiba, 2009). The greater the level of cytotoxicity of the pulp capping material, the greater the inflammatory response will be in intensity and duration. Prolonged inflammation delays the formation of a calcified barrier of sufficient thickness to protect the pulp from further microbial invasion.

Calcium hydroxide, the standard for pulp capping materials prior to MTA, has been demonstrated to provide variable and unpredictable outcomes. Calcium hydroxide does not adapt closely to dentin, is highly cytotoxic in cell culture, does not promote consistent odontoblast differentiation, and results in reparative dentin tunnel defects (Bogen, Kim, \& Bakland, 2008). Calcium hydroxide limitations are related to three major causes of pulp cap failure: the porosity of the dentinal bridge, poor adherence to dentin, and the failure to provide a long-term seal against microleakage (Paranjpe et al, 2010). Unlike calcium hydroxide, MTA has demonstrated material characteristics that maintain the integrity of pulp tissue by inducing the formation of a thicker dentinal bridge with a correspondingly lower inflammatory response (Cavalcanti, Rode, Franca, \& Marques, 2011).

The first immune cells to reach the damaged pulp are neutrophils. Neutrophils play a critical role in releasing cytokines in phagocytosis (Gomes, Gomes-Filho, \& Oliveira, 2010). Cavalcanti et al. (2011) presented in vitro evidence that human neutrophils can be induced to increase production of interleukin-I $\beta$ (IL-I $\beta$ ) by exposure to MTA. IL-I $\beta$ is known to increase collagen synthesis.

The release of cellular inflammatory cytokines such as IL-1 $\beta$ and IL-8 by neutrophils during the inflammatory process is important for dental pulp repair. When compared and tested against calcium hydroxide, MTA was able to induce a significantly greater increase in IL-1 $\beta$. IL-1 $\beta$ is a proinflammatory cytokine that plays a major role in the cellular immune response 
produced just after tissue injury. In vitro and in vivo studies have shown that MTA is able to increase production of IL-1 $\beta$ by macrophages, neutrophils and mast cells (Cavalcanti et al., 2011).

According to Yasuda, bone morphogenic compounds (BMPs) are present in dental pulp fibroblasts (Yasuda, Ogawa, Arakawa, Kadowaki, \& Takashi, 2008). Earlier studies had demonstrated that BMP-2 is expressed along with its receptor in human dental pulp (Gu, Smoke, \& Rutherford, 1996). It is also known that recombinant human BMP-2 induces dentin bridge formation on canine amputated pulp (Nakashima, Nagasawa, Yamada, \& Reddi, 1994). Yasuda previously reported that BMP-2 accelerated the differentiation of human pulp cells into odontoblasts. MTA also significantly increased BMP-2 protein production in dental pulp fibroblasts. Therefore it is hypothesized that BMP-2 is involved in MTA-induced mineralization (Yasuda et al., 2008).

During dentin formation, odontoblasts synthesize and secrete noncollagenous proteins into an extracellular matrix. From this class of proteins, dentin sialoprotein, osteopontin, osteocalcin, type 1 collagen, and alkaline phosphatase, all are observed to play a role in reparative dentin formation and all are specific markers for the presence of odontoblasts (Paranjpe, Zhang, \& Johnson, 2010). Dental pulp stromal cells (DPSC) are known to secrete angiogenic factors which are critical to wound repair, vascularization, the inflammatory process and cell migration (Paranjpe, Zhang, \& Johnson, 2010). The dental pulp also contains postnatal stem cells which are capable of differentiation into dentin and pulp-like regeneration cells (Paranjpe, Zhang, \& Johnson, 2010). Of particular note, MTA has been demonstrated to upregulate the levels of the cellular products necessary for reparative dentin bridge formation (Paranjpe, Zhang, \& Johnson, 2010) (Fig. 5). 


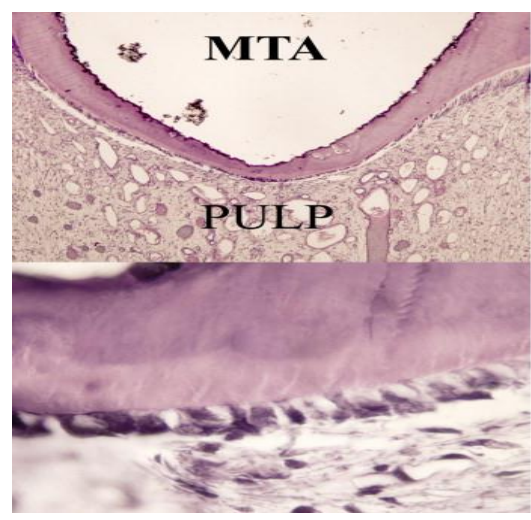

(Asgary et al., 2008)

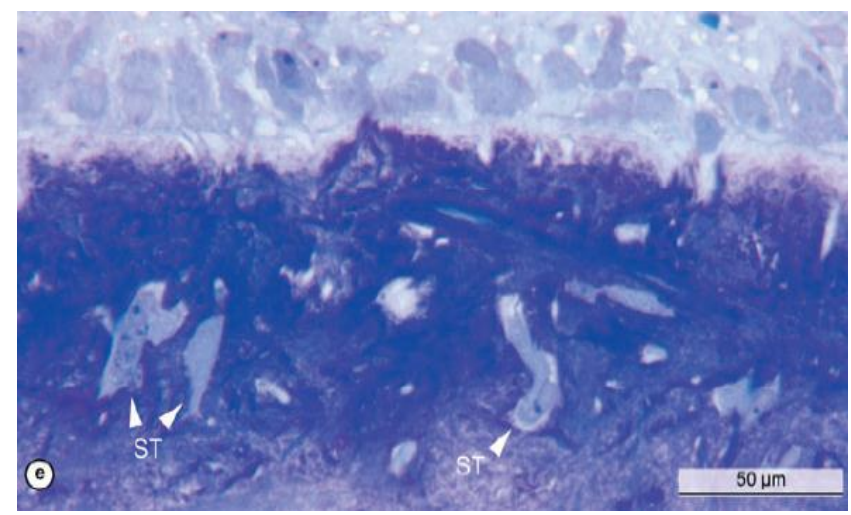

(Nair, Duncan, Pitt Ford, \& Luder, 2008)

Figure 5.

Top Left: (x100) Dentin Bridge Formation at MTA - Pulp Interface Bottom Left: (x1000) Formation of ondontoblast like cells, Dentin \& Dentinal Tubules Right: (Original magnification x600) Cuboidal pulpal cells lining the hard tissue barrier, (White Arrows) Islands of pulpal soft tissue enclosed within hard tissue barrier

Holland et al (2001) observed granulations nearest to the opening of dental tubules that were filled with MTA in an animal model (Asgary, Eghbal, Parirokh, Ghanavati, \& Rahimi, 2008). They reported that these structures were similar to calcite crystals observed with calcium hydroxide pulp caps. According to Seux, Couble, Hartmann, Gauthier, \& Magloire, (1991) calcite crystals attract fibronectin, which is responsible for celluar adhesion and differentiation, a benefit for hard tissue formation.

It is generally accepted that mechanical or accidental pulp exposure events result in a more favorable prognosis when compared to carious pulp exposures relative to continued pulp vitality with dentinal bridge formation. Carious exposures are complicated by increased pulpal inflammation due to the presence of bacteria and their metabolic products which interfere with the reparative pulpal response (Nair, Duncan, Pitt Ford, \& Luder, 2008). It is not clear though, whether the characteristics of the materials placed and the subsequent response of the vital pulp to those materials, or the ability of the material to provide a seal against bacterial ingress, is the 
key to success. It may very well be a combination of both. When bacterial by-products induce pulpal inflammation, compromise immune response and impede cellular differentiation and recruitment, normal pulpal repair mechanisms may not function properly (Bogen, Kim, \& Bakland, 2008).

A thorough review of the literature related to MTA pulp capping reveals that the majority of studies have been completed on healthy, electively exposed, intact pulps of rats, cats, dogs, chimpanzees, and humans. There is a higher success rate when capping mechanically exposed healthy pulps as opposed to pulps exposed through carious penetration (Tabarsi et al., 2010).

Six studies have been published using MTA to treat carious pulp exposures and traumatic fracture injuries involving the pulp. One study, by Mente et. al (2010) and another by BarrieshiNusair and Qudeimat (2006) and a third by Qudeimat, Barrieshi-Nusair, and Owais (2007), used a single visit protocol. One study each by Bogen (2008), Witherspoon (2006), and Farsi (2006) used a two-appointment protocol. Mente, in a single visit protocol study of 122 cases, using $0.12 \%$ chlorhexidine for disinfection, compared the success of calcium hydroxide $(60 \%)$ to that of MTA (78\%). This study revealed a dramatic, long-term failure of calcium hydroxide after three years (Mente et. al, 2010).

In the first Barrieshi-Nusair, Qudeimat study of twenty-eight carious permanent first molars, using a single visit protocol, 100\% success was reported (Barrieshi-Nusair \& Qudeimat, 2006). In the second Qudeimat, Barrieshi-Nusair, and Owais study, a comparison of calcium hydroxide to MTA in a single visit protocol of carious first permanent molars, success of calcium hydroxide (91\%) and MTA (93\%) were reported (Qudeimat, Barrieshi-Nusair, \& Owais, 2007). Bogen, in a two appointment study of carious exposures, using sodium hypochlorite for disinfection, reported $97.6 \%$ success. Witherspoon in a study of nineteen cases of carious and 
traumatic exposures, in a two appointment protocol, using sodium hypochlorite for disinfection, reported 70\% (15) healed, 23\% (3) healing, and 7\% (1) failure. Farsi, in a two appointment protocol, reported $93.3 \%$ success $(28 / 30)$ at twenty-four months.

Kakehashi et al. (1966) clearly established the role that bacteria play in pulpal necrosis. Germ-free, the injured pulp retains the ability to heal and deposit dentin material at the site of the injury. MTA ses ability to provide a bacteria impenetrable seal at the pulp/perforation interface provides a germ-free environment (Witherspoon, 2008). It follows that healing of the dental pulp is affected not by the type of medicament placed, but rather the ability of that material to prevent and maintain future micro-leakage (Nair et al, 2008).

Pulp capping has long been considered to be a procedure best limited to young teeth because of their greater reparative potential and greater level of blood flow and cell density. Retrospective studies however, clearly show that the age of the patient should not be a limiting factor in pulp capping therapy (Simon et al., 2010).

Pulp repair is a complex process whose specific sequence of histological mechanisms and interactions is not yet fully understood (Cavalcanti et al., 2011). Additional research is necessary related to the inflammatory and reparative processes in order to reveal the specific relationships between cytotoxic effects, cell recruitment and migration, and cytokine production.

An ideal endodontic repair material must seal the pathways of communication in and out of the root canal system, be nontoxic, non-carcinogenic, nongenotoxic, biocompatible, dimensionally stable, and insoluble in fluids. As recommended by the American Association of Endodontists (AAE), any use of a new material should be based on laboratory, biologic, and clinical studies (Parirokh \& Torabinejad, 2010). 
MTA is a mixture of refined Portland cement and bismuth oxide (Roberts, Toth, Bezins, \& Charlton, 2008). Bismuth oxide has been added to provide radiopacity. MTA is composed of tricalcium silicate, bismuth oxide, dicalcium silicate, tricalcium aluminate, gypsum, calcium sulfate dihydrate, silicate oxide, and tetra calcium aluminoferrite. MTA also contains trace constituents of free crystalline silica, calcium oxide, magnesium oxide, and potassium and sodium sulfate (Witherspoon, 2008). Hydration of the powder results in a colloidal gel composed of calcium oxide crystals in an amorphous structure. The hydrated compound is: $33 \%$ calcium, $49 \%$ phosphate, $6 \%$ silica, $3 \%$ chloride and 2\% carbon (Witherspoon, Small, \& Harris, 2006). The hydrated gel sets in less than 3 hours (Witherspoon, Small, \& Harris, 2006).

Studies have shown that the use of local anesthetic, saline or chlorhexidine can have negative effects on outcomes by diminishing the amount of water present for the proper set of the MTA, and for the conversion of calcium oxide to free calcium ions when MTA is prepared with water (Roberts, Toth, Berzins, \& Charlton, 2008). Compounds such as chlorhexidine may also have negative effects on the pleuripotent cells of the pulp (Roberts, Toth, Berzins, \& Charlton, 2008).

Although MTA does not have calcium hydroxide in its composition, calcium oxide is one of its components, which can form calcium hydroxide in reaction with water (Asgary et al., 2008). Calcium hydroxide has been described as a compound with direct effect on microvasculature resulting in less plasma outflow, which favors a calcific response in the adjacent pulp tissue.

Unfavorable qualities of MTA include high cost, difficult handling characteristics, and a three-hour setting duration (Parirokh \& Torabinejad, 2010). Conversely, the cost of MTA diminishes when the expense of pulp capping is compared to that of endodontic treatment. 


\section{Materials and Methods}

\section{Candidate Selection}

Forty-eight procedures were completed over a one-year period by the same provider in a graduate endodontic specialty residency clinic. The patients were either referred by private practitioners or were referred from the Urgent Care Clinic or Pediatric Dental Department of the same facility.

Of the forty-eight procedures, twenty-seven procedures were available for follow-up. Twenty-three patients representing twenty-seven procedures returned for recall as instructed, seven male and sixteen female. The twenty-three patients available for recall ranged from seven to twenty-five years of age.

Twenty-three of the procedures presented with deep caries in non-restored permanent teeth. Four procedures presented with traumatic pulp exposures of maxillary anterior teeth. A clinical diagnosis of reversible pulpitis was established through pulp testing and dental history. No control group was included in this study because the objective was to evaluate pulpal survival using one specific protocol.

\section{Tooth Selection}

Clinical examination also included a confirmation of absence of pain to percussion and a normal response to cold (Coltene/Whaledent Inc., Hygenic ENDO I·C E $®)$. The traumatic pulp exposure cases of maxillary anterior teeth presented with clinically observable pulp exposures. These cases were subjected to the same reversible pulpitis diagnostic criteria as the cariously involved cases. All periodontal probing was found to be within the normal range, with gingival attachment intact and no evidence of sinus tract or swelling in adjacent tissues. All radiographs of the carious cases confirmed deep caries in close proximity to the pulp chamber with no 
evidence of thickened periodontal ligament, furcation radiolucency, internal resorption, or periradicular pathosis. The radiograph was considered critical to an accurate diagnosis of reversible pulpitis. Each cariously involved tooth in the study was examined thoroughly in order to exclude cases of irreversible pulpitis, and each was evaluated with a periapical radiograph. Periodontal probing was performed and all teeth were evaluated for mobility.

\section{Treatment}

The patients in this study had been referred to the endodontic department for treatment due to the possibility of the need for endodontic therapy subsequent to carious pulp exposure or trauma. The diagnostic protocol as previously described was completed for all cases. Local anesthetic (Lidocaine $\mathrm{HCl}$ 2\%, 1:100,000 epinephrine, Cook-Waite) was administered in all cases according to acceptable infiltration and nerve block techniques. No patients reported discomfort or pain during the procedure. A dental dam was placed for all procedures to ensure isolation from the oral environment. Gross caries removal was achieved during cavity preparation using sterile high speed, cross-cut, fissure carbide burs under continuous water coolant. Sterile carbide burs were also used in low speed hand pieces to remove deeper caries. Final removal of caries was often completed with sterile spoon excavators (Fig. 6). The exposed pulps of the trauma cases were prepared with a water-cooled, high-speed handpiece and a sterile \#2 round carbide bur to a depth of approximately $2.0 \mathrm{~mm}$ as described by Cvek (Karabucak, Li, Lim, \& Iqbal, 2005). 

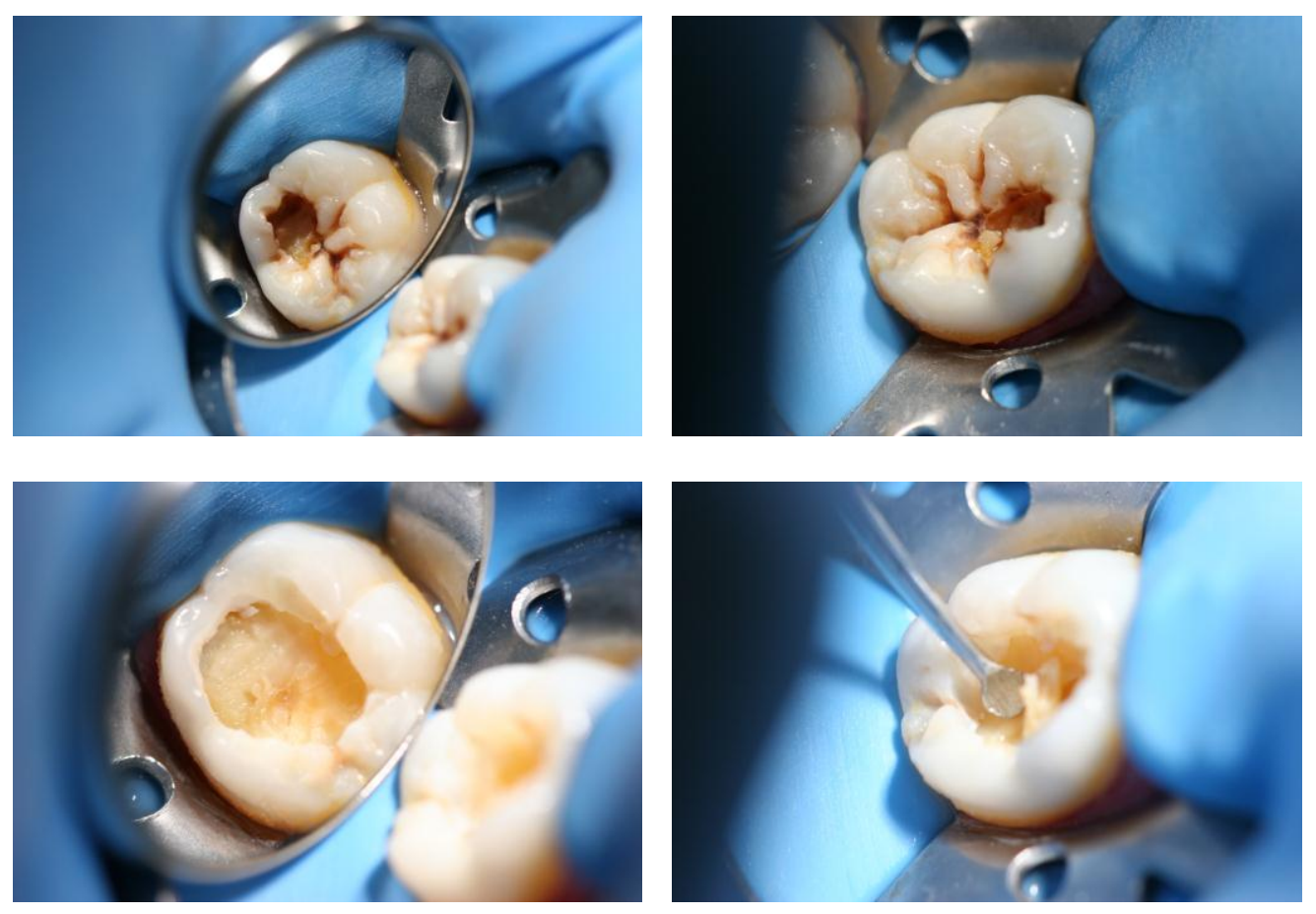

Figure 6. Top: Gross Caries (\#19), Bottom: Excavation of Caries

All treated teeth resulted in vital pulp exposure of varying diameters. Although some exposures were limited in size to approximately $2-3 \mathrm{~mm}$, many of the carious exposures were as large as 4-6 mm or greater. After complete caries removal, the cavity preparation was thoroughly cleansed with a sterile cotton pellet saturated in $2.5 \%$ sodium hypochlorite as described by Bogen in Ingle"s Endodontics 6 (Ingle, Bakland, \& Baumgartner , 2008). The author was unable to locate any other study that involved pulpal exposures of this size. All known mechanical exposure studies are of $2 \mathrm{~mm}$ or less. The $\mathrm{NaOCl}$ pellet was allowed to remain in the cavity preparation for up to five minutes for hemorrhage control. The preparation was then dried with syringed compressed air (Fig. 7, 8). 


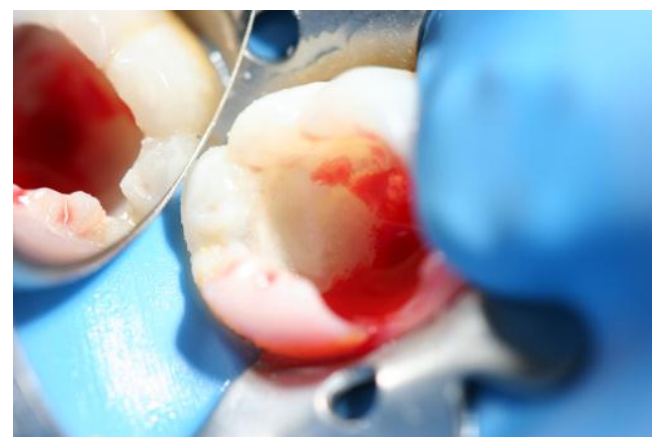

Figure 7. Hemorrohagic Pulp

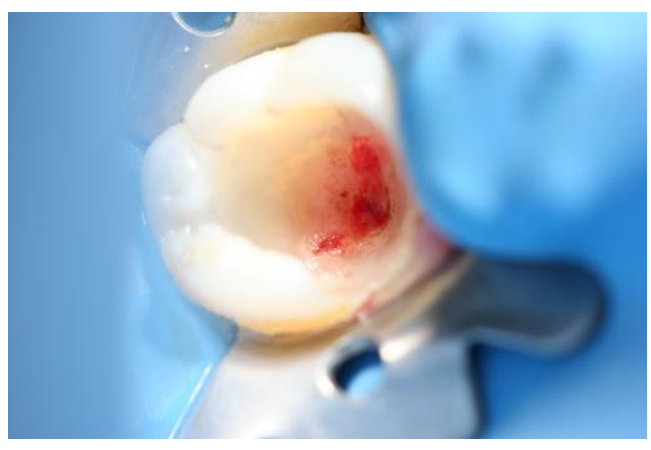

Figure 8. Hemorrhage Controlled with $\mathrm{NaOCl}$

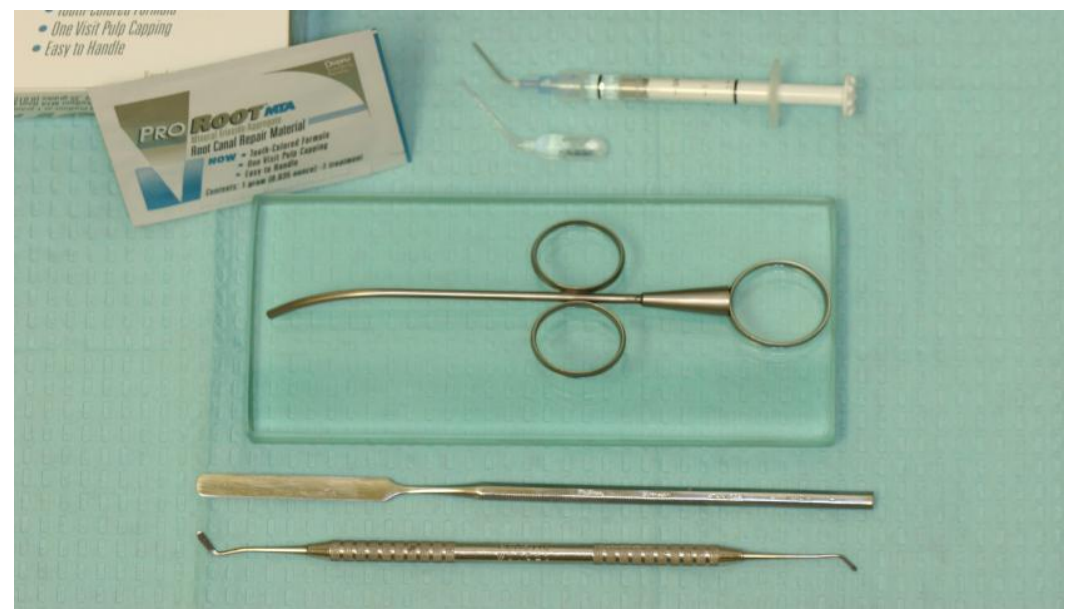

Figure 9. Armamentarium-Glass Slab, Bone Carrier Device, MTA, Sterile Water Syringe or Pipette, Spatula, PFI Instrument

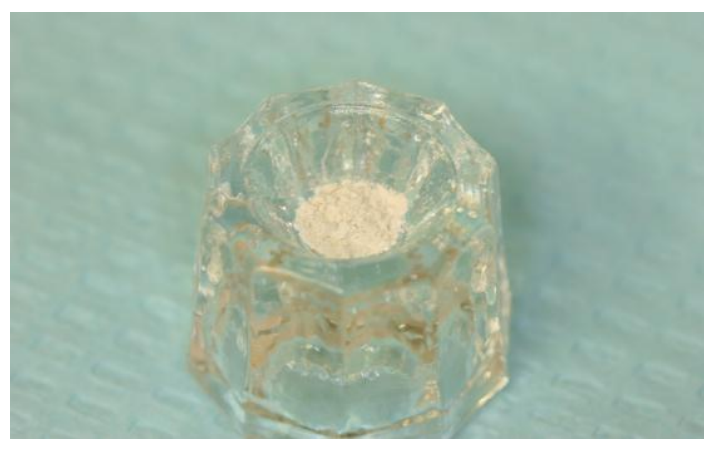

Figure 10. Fractional Dose MTA powder

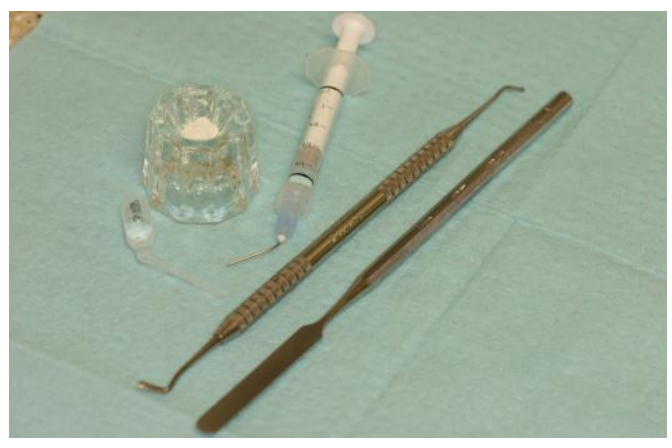

Figure 11. MTA Dose, Sterile Water, Spatula, PFI Instrument 


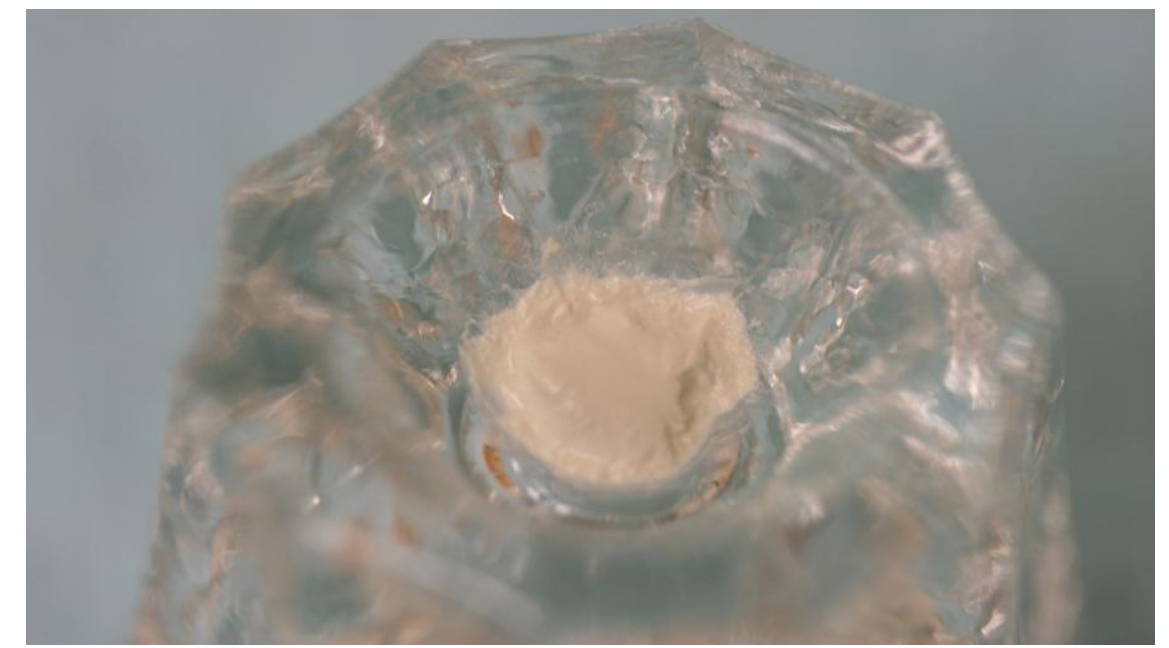

Figure 12. Wet MTA, Powder to Sterile Water 3:1 Ratio

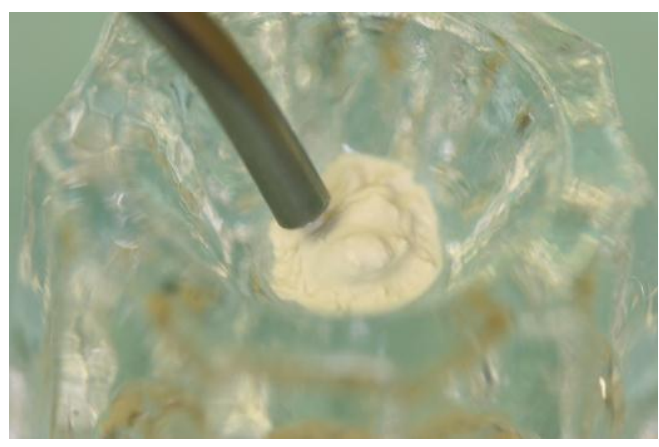

Figure 13. Loading Bone Carrier Device

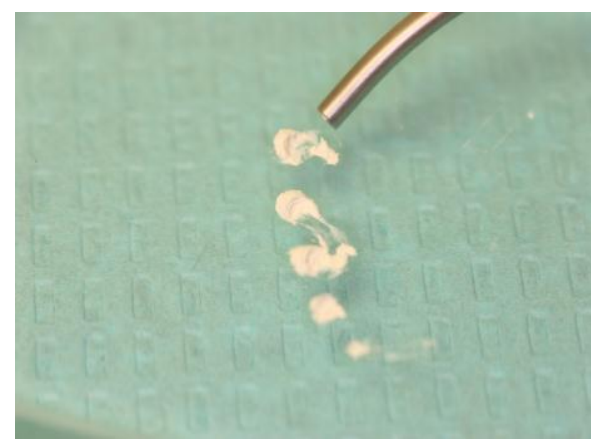

Figure 14. Dispensing desired amount onto glass slab for demonstration

White MTA (Pro-Root MTA, Dentsply Tulsa Dental, Tulsa, OK) was prepared according to the manufacturers ${ }^{\text {ee }}$ instructions in a 3:1 ratio of MTA material to sterile water (Fig. 9, 10, 11, 12). The MTA was then placed directly over the pulp exposure and as much of the dentin floor of the preparation as possible. In this study, MTA was delivered to the floor of the cavity preparation with an MTA carrier delivery device (CK Dental Industries), which afforded simple delivery. The entire pulpal floor was often covered with one or two syringe load deliveries (Fig. $13,14)$.

A perimeter margin of 1.5-2.0 $\mathrm{mm}$ of exposed dentin and enamel remained for restoration adhesion. The MTA layer thickness ranged from approximately 1.5 to $3.0 \mathrm{~mm}$. This 
particular placement technique was found to resolve one of the handling characteristic difficulties. Rather than attempting to place a small patch of MTA over the exposure only, layering the dentin floor takes advantage of the extremely small particle size of the MTA preparation which facilitates material placement and enhances the seal against microleakage (Fig. 15, 16).

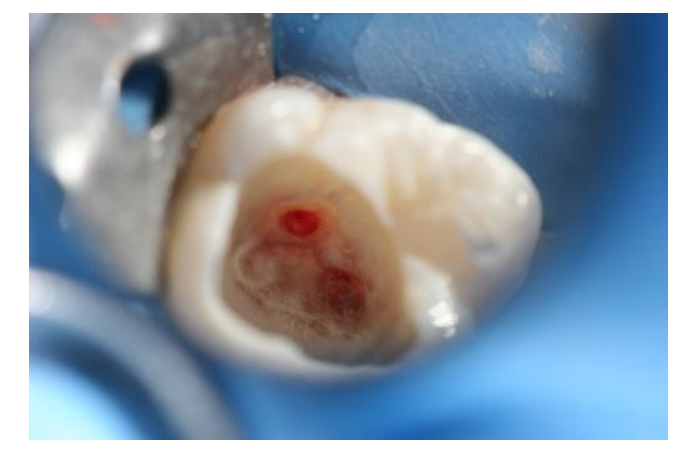

Figure 15. Large Pulpal Exposure

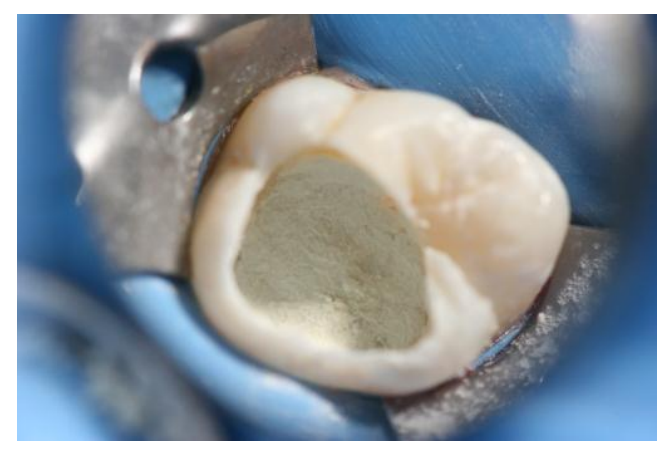

Figure 16. 1.5 mm MTA Layer

The one appointment protocol requires the placement of a glass ionomer (GC Fuji Lining ${ }^{\mathrm{TM}}$ LC) base or liner over the entire MTA surface (Ingle, Bakland, \& Baumgartner, 2008) (Fig. 17, 18). Final restoration consisted of a bonded Class I or II composite restoration (Prisma ${ }^{\circledR}$ TPH ${ }^{\circledR 3}$, DENTSPLY International) (Fig. 19, 20). The one-visit protocol is more cost effective by eliminating the need for a second visit. The single visit protocol also provides a completed final restoration while maintaining ideal isolation conditions, decreasing the possibility of bacterial contamination from leakage of a temporary restoration or isolation error during a second appointment. 


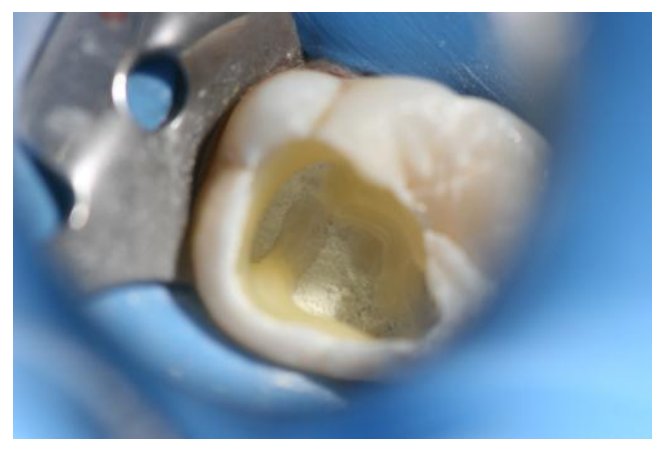

Figure 17. Glass Ionomer Partial Coverage

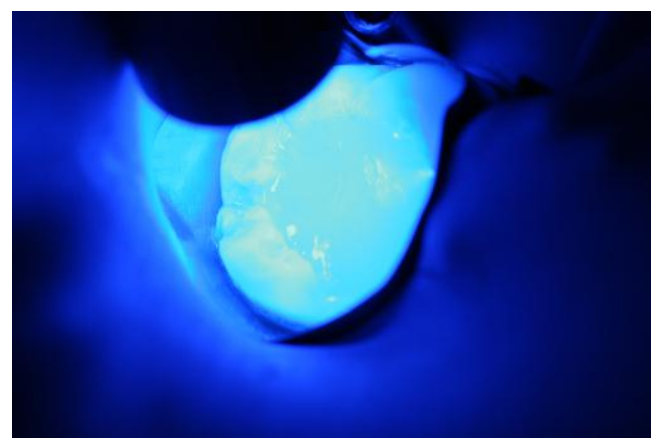

Figure 19. Light Cure Composite

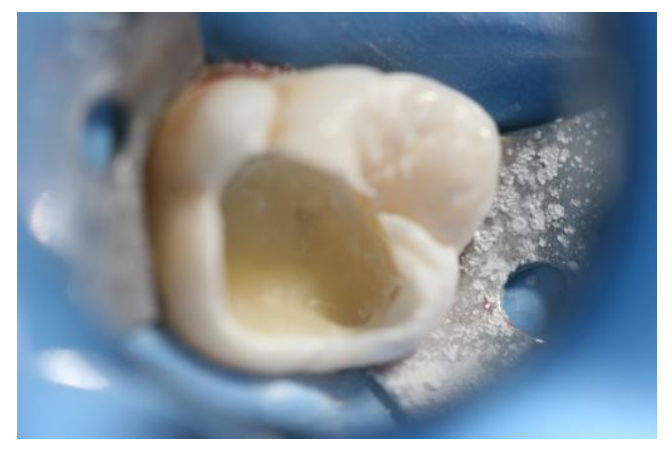

Figure 18. Glass Ionomer Full Coverage

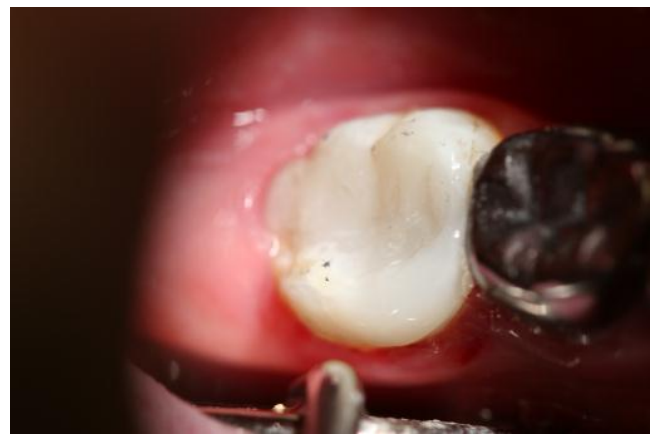

Figure 20. Completed Restoration

Final restorations in this study were mostly Class I \& II. Some cases were four or more surface complex posterior restorations. Maxillary anterior trauma cases required complex multiple surface, core-type restorations and involved restoration of the incisal edge (Fig. 21, 22).

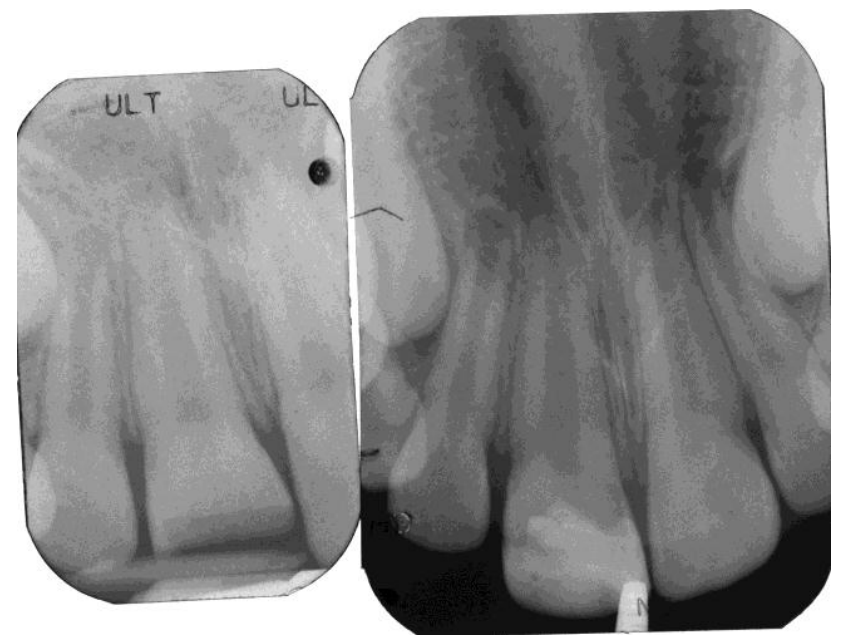

Figure 21. Maxillary Incisor (\#8) F9, Pre-Op.

Figure 22. 5 Month Recall 


\section{Post-Operative}

The patient and the parent/guardian were advised to contact the department if any painful symptoms occurred at any time. For the purpose of this study the recall period was extended to demonstrate a longer term, beneficial outcome. At the recall appointment, the MTA restored tooth was evaluated for restoration integrity, pain to percussion or biting, patient reported symptoms, and response to a cold stimulus. Bitewing and periapical radiographs were taken when possible. Two very young patients (Case 3 and 7) were unable to tolerate posterior periapical radiographs that captured the entire apical root. These two patients tolerated periapical radiographs at the treatment appointment due to the effect of local anesthestic. Recall periapical radiographs of diagnostic quality, could not be obtained on two patients.

\section{Success/Failure}

A successful treatment outcome was evaluated according to the following criteria: the tooth must be present with no radiographic evidence of periapical pathology, no pain to percussion or biting, no subsequent endodontic treatment, and a positive response to cold stimulus (Coltene/Whaledent Inc., Hygenic ENDO I·C·E®).

A failed treatment outcome was judged to be any of the following: extracted or endodontically treated teeth, reported spontaneous pain, radiographic evidence of periapical pathology, pain to percussion or biting, presence of a sinus tract or swelling of adjacent tissues, or no response to cold stimulus.

Twenty-three patients representing twenty-seven procedures returned for recall as instructed. Three of the procedures resulted in subsequent endodontic therapy due to patient reported symptoms of pain. One procedure was treated endodontically at the insistence of the 
referring dentist in spite of findings of pulpal preservation success at five weeks post treatment. Twenty-three procedures were found to be successful according to the aforementioned criteria.

\section{Results}

A total of twenty-three patients representing twenty-seven procedures were available for recall. Of the twenty-seven returning cases, twenty-three procedures were successful, and four were reported as failures. The final success/failure results demonstrate a success of $85 \%(23 / 27)$. If the procedure that was terminated at the insistence of the referring dentist is eliminated (23/26), the success/failure result increases to $88 \%$.

The average recall interval for the twenty-three successful procedures is 11.9 months. The four failed procedures failed in an average time of 101.5 days. If the one procedure with the longest time to failure is eliminated (305 days), the average days to failure falls to 33.7 days. Failed procedures are most often reported within a very short period of time following treatment.

Twenty-one of the twenty-seven procedures available for recall were completed on carious molars. Two procedures were completed on bicuspids. Four procedures were completed on traumatically fractured maxillary incisors. The twenty-three patients available for recall ranged from seven to twenty-five years of age. The average age of the patients representing the twenty-seven procedures available for recall is 12.9 years. 
Table 1. CASES AVAILABLE FOR RECALL

\begin{tabular}{|c|c|c|c|c|c|}
\hline Patient \# & Procedure & Success/Failure & $\begin{array}{c}\text { AGE } \\
\text { Year-Month }\end{array}$ & Tooth \# & $\begin{array}{c}\text { Recall } \\
\text { Interval } \\
\text { Months }\end{array}$ \\
\hline \multirow[t]{2}{*}{1} & 1 & $\mathrm{~S}$ & 09-07 & 30 & 16 \\
\hline & 2 & $\mathrm{~S}$ & 09-07 & 14 & 16 \\
\hline 2 & 3 & $\mathrm{~S}$ & 07-09 & 19 & 16 \\
\hline \multirow[t]{2}{*}{3} & 4 & $\mathrm{~S}$ & $11-06$ & 19 & 16 \\
\hline & 5 & $\mathrm{~S}$ & $11-06$ & 30 & 16 \\
\hline 4 & 6 & F & $13-02$ & 30 & Failed \\
\hline 5 & 7 & $\mathrm{~S}$ & $08-05$ & 19 & 14 \\
\hline 6 & 8 & $\mathrm{~S}$ & $14-08$ & 18 & 15 \\
\hline 7 & 9 & $\mathrm{~S}$ & $09-11$ & 03 & 12 \\
\hline 8 & 10 & F & $16-02$ & 31 & Failed \\
\hline 9 & 11 & $\mathrm{~S}$ & $15-07$ & 18 & 12 \\
\hline 10 & 12 & $\mathrm{~S}$ & $11-04$ & 08 & 07 \\
\hline \multirow[t]{2}{*}{11} & 13 & $\mathrm{~S}$ & $20-06$ & 31 & 14 \\
\hline & 14 & $\mathrm{~S}$ & $20-07$ & 19 & 14 \\
\hline 12 & 15 & $\mathrm{~S}$ & $17-11$ & 12 & 14 \\
\hline \multirow[t]{2}{*}{13} & 16 & $\mathrm{~S}$ & $16-06$ & 30 & 12 \\
\hline & 17 & $\mathrm{~S}$ & 16-09 & 19 & 09 \\
\hline 14 & 18 & $\mathrm{~S}$ & $12-09$ & 19 & 11 \\
\hline 15 & 19 & $\mathrm{~F}$ & $25-06$ & 09 & Failed \\
\hline 16 & 20 & $\mathrm{~S}$ & $10-06$ & 30 & 13 \\
\hline 17 & 21 & $\mathrm{~F}$ & $14-10$ & 30 & Withdrawn \\
\hline 18 & 22 & $\mathrm{~S}$ & 09-01 & 08 & 06 \\
\hline 19 & 23 & $\mathrm{~S}$ & $07-04$ & 08 & 10 \\
\hline 20 & 24 & $\mathrm{~S}$ & $08-08$ & 19 & 10 \\
\hline 21 & 25 & $\mathrm{~S}$ & $07-02$ & 19 & 06 \\
\hline 22 & 26 & $\mathrm{~S}$ & $11-05$ & 13 & 04 \\
\hline 23 & 27 & $\mathrm{~S}$ & 09-06 & 14 & 12 \\
\hline
\end{tabular}

Table 2. FAILURE CASE

\begin{tabular}{ccccc} 
ID & Tooth \# & Days to Failure & Outcome & Diagnosis \\
$\mathbf{6}$ & 30 & 305 days & Endodontic tx. & Irrev. pulpitis \\
$\mathbf{1 0}$ & 31 & 15 days & Endodontic tx. & Irrev. pulpitis \\
$\mathbf{1 9}$ & 09 & 29 days & Endodontic tx. & Irrev. pulpitis \\
$\mathbf{2 1}$ & 30 & 57 days & Endodontic tx. & $\begin{array}{c}\text { General dentist } \\
\text { directive }\end{array}$ \\
\hline
\end{tabular}


STATISTICAL ANALYSIS: SUCCESS/FAILURE

Outcome

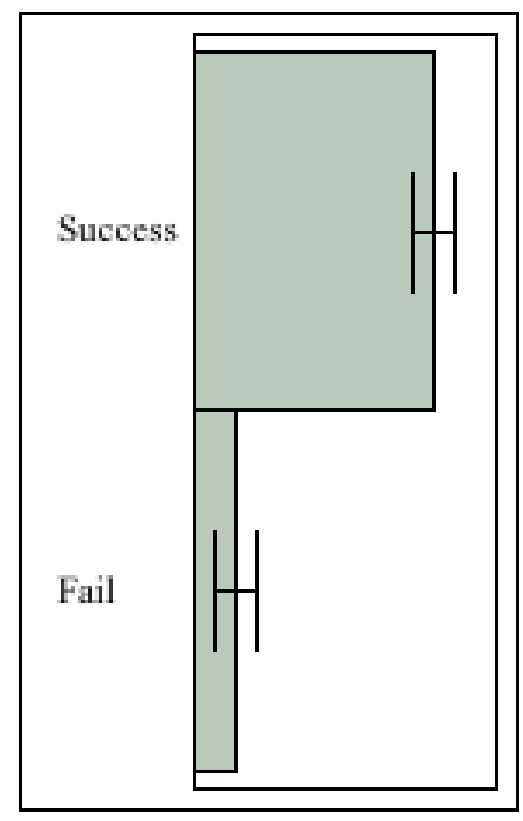

Frequencies

Level Count Prob

Fail 40.14815

Success $\quad 23 \quad 0.85185$

Total $27 \quad 1.00000$

N Missing

0

2 Levels

Confidence Intervals

Level

Fail

Success

Total

Count

$4 \quad 0.14815$

$23 \quad 0.85185$

27

Note: Computed using score confidence intervals
Lower CI Upper CI

$0.059159 \quad 0.324787$

0.675213

0.940841

1-Alpha

0.950

0.950 


\section{Discussion}

The reported results of this retrospective study represent the success or failure of twentyseven MTA pulp cap procedures. Although forty-eight procedures were completed, no conclusions can be drawn regarding the twenty-one procedures that were unavailable for recall evaluation. Bogen observed that compliance rates for follow-up with child patients can be mediocre as some parents lack basic oral health knowledge and do not practice preventive care (Ingle, Bakland, \& Baumgartner, 2008). An observation can be made that failed procedures are far more likely to report for treatment than successful cases will be available for recall. An inference may be made that the patients unavailable for recall benefited from successful outcomes. There is no factual or statistical evidence for this inference.

In a very similar study by Bogen, Kim, and Bakland (2008), it was stated that although there were only a small number of cases, the results of this MTA direct pulp cap study, following a one-visit protocol, showed that this procedure can achieve a long-term favorable outcome. Since this study did not have a control group, the results provide, within the limitations of the study, a relatively low level of scientific evidence. The data offer an alternative treatment option for certain patients who are not diagnosed with irreversible pulpitis.

\section{Summary and Conclusions}

The perceived high cost of MTA use is overcome by completing multiple procedures from one $1.0 \mathrm{~g}$ foil packet of MTA as packaged by the manufacturer. Each procedure requires far less than $1.0 \mathrm{~g}$ of material, and the package can be heat sealed to prevent absorption of environmental humidity, thus preserving the contents for several procedures. Other storage methods that seal out or eliminate environmental humidity exposure are also acceptable. New packaging in a single dose would appear to be the ideal solution to cost issues. 
Difficulty in handling MTA can be minimized with proper hemorrhage control, rubber dam isolation and experience gained through the successful completion of multiple treatments. When prepared to the proper consistency, MTA is not difficult to handle.

This study further supports previous reports of a high percentage of long term success with MTA pulp capping procedures of both carious and traumatic pulp exposures. Conclusions can be drawn that case selection of reversible pulpitis can be difficult to determine. Following removal of cariously involved tooth structure, the presence of a vital, hemorrhagic pulp and hemorrhage control with sodium hypochlorite may be the best predictors of success.

Successful outcomes are also predicated upon disinfection of the preparation with sodium hypochlorite, eliminating as many bacteria as possible, and the ability of the pulp capping material to provide a long-term bacterial static seal. MTA demonstrates the ability to provide an adequate seal. MTA also appears to provide bioactive agents at the pulpal tissue interface that facilitate pulpal regeneration and dentinal bridge formation, providing for a high percentage of long-term favorable outcomes (Fig. 23, 24, 25, 26, 27). Future studies will provide greater histological detail on the regenerative process, leading to new bioactive materials that will provide greater predictability to pulp capping procedures. 


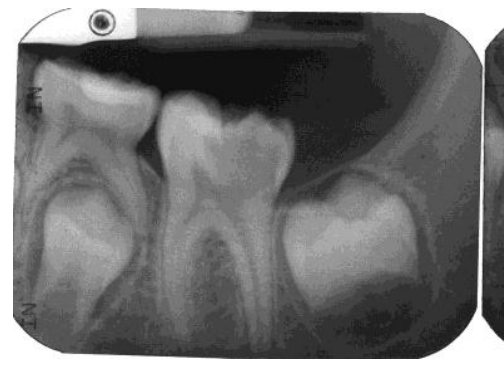

Figure 23. Mandibular Left First Molar (\#19), F8, Pre-Op.

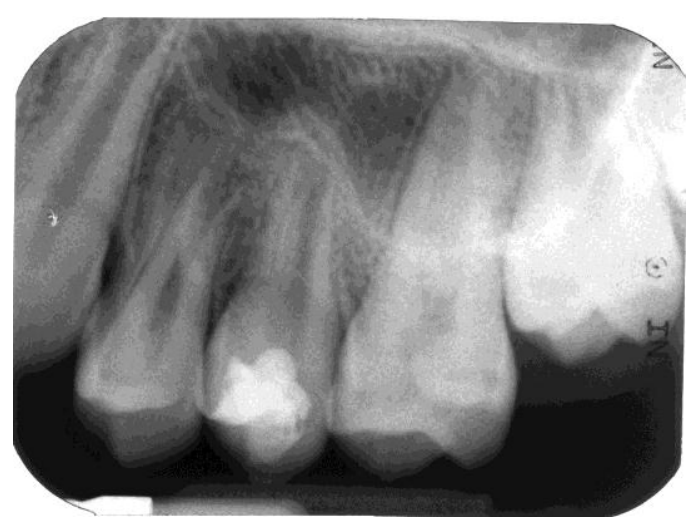

Figure 26. Maxillary Left Second Bicuspid \#13, M11, Post-Op.

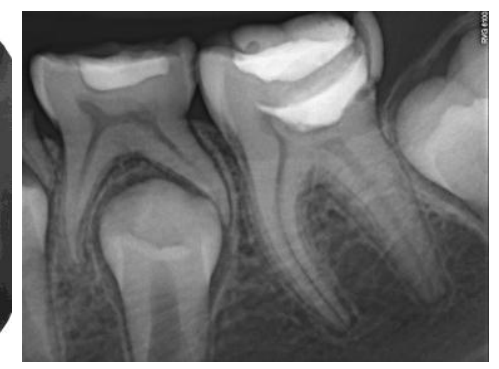

Figure 25. Dentin Bridge, 10 Month Recall

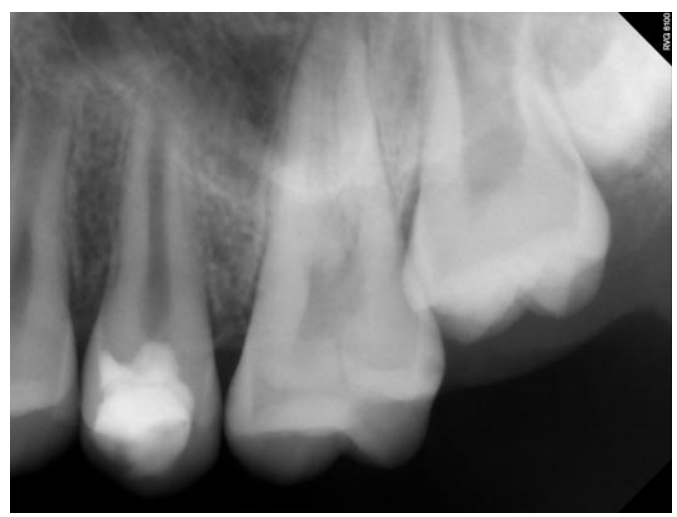

Figure 27. Apexogensis Progression, 3 Month Recall 


\section{References}

Accorinte, M.L.R., Loguercio, A.D., Reis, A., O.Bauer, J.R., Grande, R.H.M., Murata, S.S., Souza, V., \& Holland, R. (2009). Evaluation of two mineral trioxide aggregate compounds as pulp-capping agents in human teeth. International Endodontic Journal, 42, 122-128.

Asgary, S., Eghbal, M.J., Parirokh, M., Ghanavati, F., \& Rahimi, H. (2008). A comparative study of histologic response to different pulp capping materials and novel endodontic cement. Oral Surgery, Oral Medicine, Oral Pathology, Oral Radiology, \& Endodontics, 106 (4), 609614. doi:10.1016/j.tripleo.2008.06.006

Barrieshi-Nusair, K.M. \& Qudeimat, M.A. (2006). A prospective clinical study of mineral Trioxide aggregate for partial pulpotomy in cariously exposed permanent teeth. Journal Of Endodontics, 32 (8), 731-735.

Blokhuis, T.J., Termaat, M.F. den Boer, F.C., Patka, P., Bakker, F.C., \& Haarman, H.J.T. (1999). Properties of calcium phosphate ceramics in relation to their in vivo behavior. Journal of trauma: Injury infection, and critical care, 48 (1), 179-186.

Bogen, G., Kim, J.S., \& Bakland, L.K. (2008). Direct pulp capping with mineral trioxide aggregate: An observational study. Journal of American Dental Association, 139 (3), 305-15. Retrieved from http://jada.ada.org.

Cavalcanti, B.N., Rode, S.M., Franca, C.M., \& Marques, M.M. (2011). Pulp capping materials exert an effect on the secretion of IL-1ß and IL-8 by migrating human neutrophils. Brazilian Oral Research, 25(1), 13-18.

Farsi, N. Alamoudi, N., Balto, K., \& Al Mushayt, A. (2006). Clinical assessment of mineral trioxide aggregate (MTA) as direct pulp capping in young permanent teeth. Journal of Pediatric Dentistry, 31 (2), 72-76. 
Gomes, A.C., Gomes-Filho, J.E., \& Oliveira, S.H. (2010). Mineral trioxide aggregate stimulates macrophages and mast cell to release neutrophil chemotactic factors: role of IL-1beta, MIP-2 and LTB (4). Oral Surgery, Oral Medicine, Oral Pathology, Oral Radiology, \& Endodontics, $109(3), 135-42$.

Gu, K., Smoke, R.H., \& Rutherford, R.B. (1996). Expression of genes for bone morphogenetic proteins and receptors in human dental pulp. Archive Oral Biology, 41, 919-23.

Guven, E.P., Yalva, M.E., Sahin, F., Yazici, M.M., Rizvanov, A.A., \& Bayirli, G. (2011). Effect of dental material calcium hydroxide-containing cement, mineral trioxide aggregate, and enamel matrix derivative on proliferation and differentiation of human tooth germ stem cells. Journal of Endodontics, 37 (5), 650-56. doi:10.1016/j.joen.2011.02.008

Hasheminia, S.M., Ghader, F., Razavi, S.M., Feizianfard, M., Gutknecht, N., \& Mir, M. (2010). A comparative study of three treatment methods of direct pulp capping in canine teeth of cats: a histologic evaluation. Lasers Medical Science, 25(1), 9-15. doi 10.1007/s10102-008-0584-9

Holland, R., Filho, J.A., de Souza, V., Nery, M.J., Bernabe, P.F., \& Junior, E.D. (2001). Mineral trioxide aggregate repair of lateral root perforations. Journal of Endodontics, 4, 281-4.

Ingle, J.I., Bakland, L.K., \& Baumgartner, J.C. (2008).Vital pulp therapy. Ingle's Endodontics 6 (pp. 1322). Hamilton, Ontario: BD Decker, Inc.

Kakehashi, S., Stanley, H.R., Fitzgerald, R.J. (1966). The effects of surgical exposures of dental pulps in germ-free and conventional laboratory rats. Oral Surgery, Oral Medicine, Oral Pathology, 20(3), 340-349.

Karabucak, B., Li, D., Lim, J., \& Igbal, M. (2005). Vital pulp therapy with mineral trioxide aggregate. Dental Traumatology, 2, 240-243. 
Mente, J...., Dreyhaupt, J., ... Pfefferle, T. (2010). Mineral trioxide aggregate or calcium hydroxide direct pulp capping: An analysis of the clinical treatment outcome. Journal of American Endodontics, 36(5), 806-13. doi: 10.1016/j.joen.2010.02.024

Nakashima, M., Magasawa, H., Yamada, Y., \& Reddi, A.H. (1994). Regulatory role of transforming growth factor- $\beta$, bone morphogenetic protein-2, and protein- 4 on gene expression of extracellular matrix proteins and differentiation of dental pulp cells. Developmental Biology, 162, 18-28.

Nair, P.N.R., Duncan, H.F., Pitt Ford, T.R., \& Luder, H.U. (2008). Histological, ultrastructural and quantitative investigations on the response of healthy human pulps to experimental capping with mineral trioxide aggregate: a randomized controlled trial. International Endodontic Journal, 41, 128-50. doi: 10.1111/j.13652591.2007.01329.x

Okiji. T. \& Yoshiba, K. (2009). Reparative dentionogenesis induced by mineral trioxide aggregate: A review from the biological and physicochemical points of view. International Journal of Dentistry, 1-12. doi: 10.1155/2009/464280

Paranjpe, A., Zhang, H., Johnson, J.D. (2010). Effects of mineral trioxide aggregate on human dental pulp cells after pulp-capping procedures. Journal of Endodontics, 36(6), 1042-47. doi: 10.1016/j.joen.2010.02.013

Parirokh, M. \& Torabinejad, M. (2010). Mineral trioxide aggregate: A comprehensive literature review_-Part III: Clinical applications, drawbacks, and mechanism of action. Journal of Endodontics, 36(3), 400-13. doi: 10.1016/j/joen.2009.09.009 
Pitt Ford, T., Mannocci, F., \& Woolford, M. (2007). Survey on the teaching and use of mineral trioxide aggregate in UK dental schools. European Journal of Dental Education, 11, 155-59.

Qudeimat, M.A., Barrieshi-Nusair, K.M., \& Owais, A.I. (2007). Calcium hydroxide vs. mineral trioxide aggregates for partial pulpotomy of permanent molars with deep caries. European Archives of Pediatric Dentistry, 8 (2), 99-104.

Roberts, H.W., Toth, J.M., Berzins, D.W., \& Charlton, D.G. (2008). Mineral trioxide aggregate material use in endodontic treatment: A review of the literature. Dental Materials 24, 149-64. doi: 10.1016/j.dental.2007.04.007

Seux, D., Couble, M.L., Hartmann, D.J. Gauthier, J.P., Magloire, H. (1991). Odontoblast-like cytodifferentiation of human dental pulp cells in vitro in the presence of a calcium hydroxidecontaining cement. Archive of Oral Biology, 36, 117-28.

Simon, S., Lumley, P.J., Cooper, P.R., Berdal, A., Machtou, P., \& Smith, A.J. (2010). Trauma and dentinogenesis: A case report. Journal of Endodontics, 36 (2), 342-44. doi:10.1016/j.joen.2009.09.021.

Tabarsi, B., Parirokh, M., Eghbal, M.J., Haghdoost, A. A., Torabzadeh, H. \& Asgary, S. (2010). A comparative study of dental pulp response to several pulpotomy agents. International Endodontic Journal, 43, 565-71. doi: 10.1111/j.1365-2591.2010.01711.x Yasuda, Y. Ogawa, M. Arakawa, T., Kadowaki, T., \& Saito, T. (2008). The effect of mineral trioxide aggregate on the mineralization ability of rat dental pulp cells: An In vitro study. Journal of Endodontics, 34(9), 1057-60. doi: 10.1016/j/joen.2008.06.007

Williams, D.F. (2008). On the mechanisms of biocompatibility. Biomaterials, 29(20), 29412953. 
Witherspoon, D.E. (2008). Vital pulp therapy with new materials: New directions and treatment perspectives - permanent teeth. Journal of Endodontics, 34(7s), S25-28 doi:10.1016/j/joen.2008.02.030

Witherspoon, D.E., Small, J.C., Harris, G.Z. (2006). Mineral trioxide aggregate pulpotomies: A case series outcomes assessment. Journal American Dental Association, 137, 610-18. 


\section{WestVirginiaUniversity.}

Office of Research Compliance

\section{IRB Protocol-Exemption}

To: $\quad$ Bagby, Michael

From: $\quad$ WVU Office of Research Compliance

Date: $\quad$ Monday, July 16, 2012

Subject: Exemption Acknowledgement

Tracking \#: $\mathrm{H}-24169$

Title: $\quad$ A Retrospective Clinical Study to Evaluate Mineral Trioxide Aggregate (MTA)As a Direct Pulp Capping Agent In a One-Visit Protocol

The above-referenced study was reviewed by the West Virginia University Institutional Review Board (IRB) and was granted exemption in accordance with 45 CFR 46.101(4).

This protocol was reviewed using the following:

This research study was granted an exemption in accordance withResearch on existing data, documents, records, pathological specimens, or diagnostic specimens [45 CFR 46.101(4)].

The following documents have been acknowledged for use in this study and are available in the BRAAN system:

Vairable ListNOTE: Please be aware that study data must be kept for up to three years after the study completion.

Thank you.
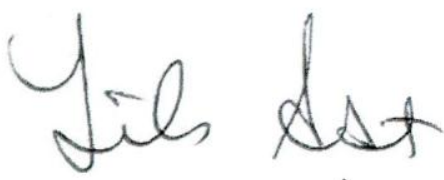

Board Designee: Ast, Lilo

Letter Sent By: Ast, Lilo, 7/16/2012 2:46 PM

Once you begin your human subject research, the following regulations apply:

1. Any modifications to the study protocol must be reviewed and acknowledged by the IRB prior to implementation.

2. You may not use a modified form until it has been acknowledged by the IRB. 